\title{
The mechanism of the rawāshin: the case study of Makkah
}

\author{
F. Al-Murahhem \\ Umm al-Qura University, Saudi Arabia
}

\begin{abstract}
This paper highlights one of the traditional architectural features in Makkah, the holy city of Islam that is located in the Hijaz region of Saudi Arabia. This element, which is called locally "roshan / roshān, pl. rawasheen / rawāshīn", is a type of projected wooden screen. It covers the façade of the building and protects it as a garment. Most, if not all, of these buildings have been demolished, due to the need for the enlargement of the area surrounding the Holy mosque to accommodate the increased number of pilgrims. Therefore, understanding the mechanism of the rawāshin could help to: emphasis its importance, reinvent a similar element and/or to preserve such an element through documentation.

This wooden garment that wraps the skin of the building has unique parts and is constructed in a way that mimics the features of the human face. That is, the upper part could be seen as the forehead, the middle part mimics the eye and the nose and the lower part as a chin. Each part, with its ornamentation, fulfils a specific function from within the house and keeps it cold and airy. The rawāshin do not just work as functional architectural elements, they also provide aesthetic benefits from inside and outside the house. This paper reflects also cultural aspects related to the architecture and inhabitation of the region and the impact of Islamic architecture in Makkah. More importantly, it echoes the harmonisation between architecture and the nature of the environment. That is to say, traditional architecture and its elements, as a source of knowledge, can give lessons in many aspects to the coming generation, including eco-architecture.

Keywords: rawasheen or rawāshīn, projected window, wooden window, traditional houses, Makkah, Saudi Arabia, Islamic architecture, dry environment, mechanism.
\end{abstract}




\section{Introduction}

Roshān or roshan (pl. rawāshīn) is an old term used for a wooden projected window found in Makkah and in some cities of the Islamic world. It was documented as "roshān" in planning and building regulation documents of the Islamic cities during the Mamlūk era (1248-1516), as Amin and Ibrahim [1] assert. In fact, the roshān is not a local term excluded to the Arabian Peninsula; it is still in use in Sawakin in Sudan and Rashid and Qusir in Egypt. The linguistic origin of the term roshān is Farsi, and it means a source of light. The historical origin is based upon the word roshān from the very distant past. The presence of the Persian in the Hijaz region and Makkah in particular was even earlier than Islam, as some studies argue [2-4]. Traditional houses in Makkah are interwoven with this wooden architectural fabric where the term is still actively used. Structurally, the roshān is usually completed with three parts (the lower part, the middle part where the openings are located and the upper part); each part has its local name. It could be seen as one separate unit to cover an opening or a side of a room, or a continuous one that envelopes the whole façade of the house, fig. 1.
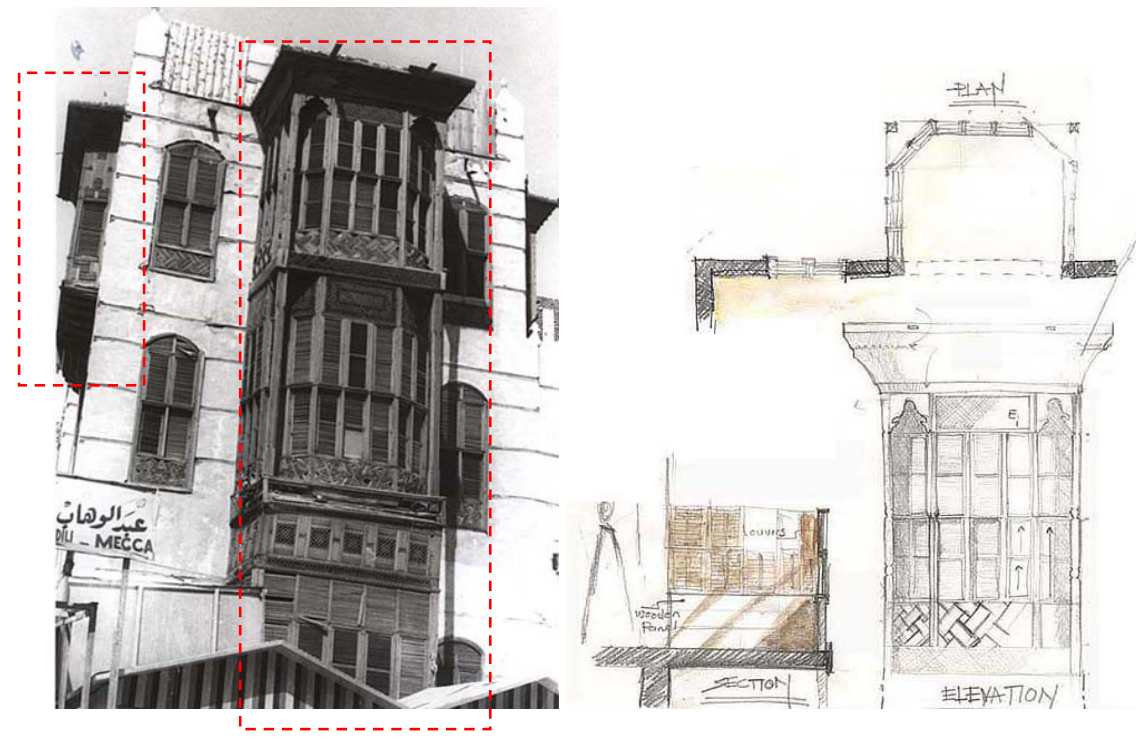

Figure 1: The roshān-separate and continuous unit.

\section{The construction of the roshān}

The traditional roshān is assembled from identical parts and units sourced locally, so that the side panels of the roshān have one standard height, which also applies to the front panel with slight variations, not in the construction but in small details, fig. 1. The variation may occur as a result of the joints between one panel and another, and in order to achieve a satisfactory general appearance of 
the roshān as a whole. This could be with the proviso that generally the width of the side panel should be equal to the distance between the uprights that divide the panels of the roshān as claimed by Hariri [5]. However, Taha [6] argues that the interior division of the upright panel has to be appropriate and coordinated, he also states that: the roshān is divided into a number of upright sections so that the horizontal aspect of the roshān should be symmetrical (in most cases) while its vertical aspect need not be symmetrical because of the variations in the component parts and their use. Thus if the roshān were made up of a vertical unit ' $X$ ' which is repeated, the unit ' $X$ ' would be a unit of, say $50-70 \mathrm{~cm}$ and the roshān would then be made up of several units.

Since the present study does not deal with the precise dimensions of the roshān, the above measurements may be taken as approximations of the example in question, i.e. $50-70 \mathrm{~cm}$ for each of the standard repeated units as a module. The internal divisions of the standard unit can be considered as horizontal units connected in sequence from bottom to top. If the standard upright unit is ' $\mathrm{X}$ ', on the inside it would be bottom $X$, upper $X$ and middle $X$ considered as separate parts. Consequently, the inside of the standard upright unit would be a unit with a horizontal measurement repeated for each of the (X) sections, fig. 2. There are also additional trimmings and extras to join the parts of the traditional roshān as a whole into one fixture. Then the various decorative and imaginative items appear inside each unit and its parts, in the plain and empty areas and the hollowed-out and projecting parts, as in fig. 2, fig. 3 .
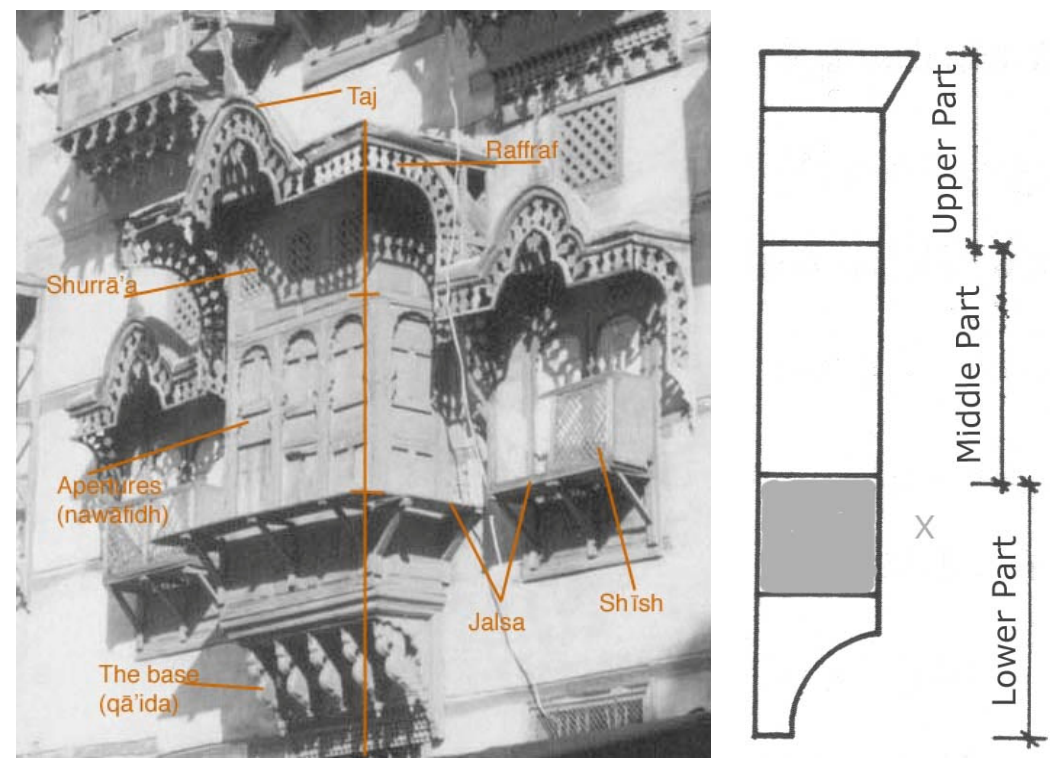

Figure 2: The roshān construction parts. 


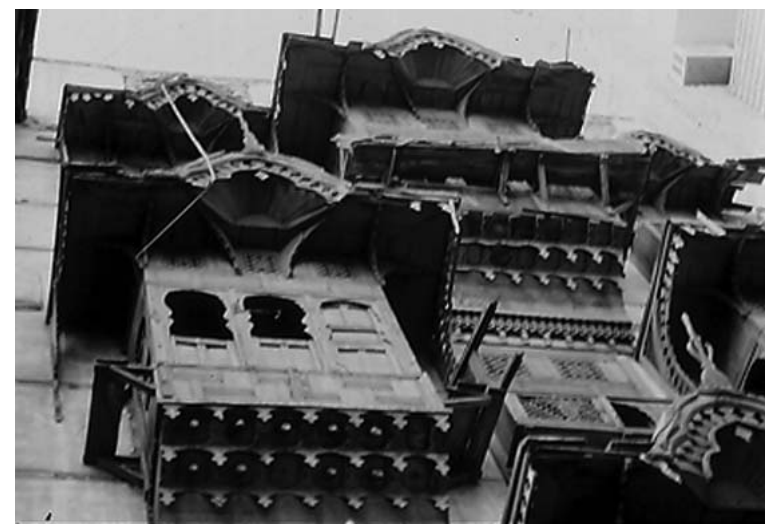

Figure 3: $\quad$ The lower and the upper treatment [11].

\subsection{The lower part}

The lower part of the roshān is made up of two sections: the support (da'ama) and the base ( $q \bar{a}$ ' $i d a$ ). This part may be decorated on the outside and plain on the inside to form a harmonious part of the interior surroundings. From inside the room it looks like a cover resting on a frame to be used for sitting. The area between the floor of the roshān and the lower panels may be covered with horizontal panels varying in height between 40 and $50 \mathrm{~cm}$. This part forms a suitable height for supporting the back of who is seated in the roshān, and gives a clear outside view as stated by Hariri [5]. In fact, the lower part is the fixed part of the roshān and its measurement varies between approximately 30 and $70 \mathrm{~cm}$.

As for the support or da'āma, the rawāshīn of Makkah rely on wooden supports (beams) between the floor and ceiling of the room, which extends by the same distance as the roshān protrudes. They are usually made of strong, squared lengths of wood, set close together, or the supports may be on both sides of the lower part of the roshān, forming an approximate triangle, fig. 2, fig. 3 . These are called locally karādī (sing. kurdi). The kurdi bears the weight of the roshān on strong wooden beams projecting from the surface of the wall at an angle of about 90 degrees. The beams are left exposed without any covering, or they are hidden behind shorings and decorated planks. These shorings may be carved or decorated. However, the rawāshin on the ground floor are set on projecting stone supports or on a projecting base wall that is built up from the ground to the level of the roshān base.

In the Hijaz region of Saudi Arabia the rawāshin of the houses are supported on projecting supports that called locally kawābill, (sing. kabuli). These kawābìl are made of wood, and their design and size varies according to the resources and taste of the householder. According to Khan [7] these wooden supports that are set inside the walls of the building to bear the weight of the rawāshin and the kawābìl are also used as decorative architectural features, some being carved in the form of peacocks, which are common features in Persia and India. 


\subsection{The middle part}

The middle part is the section that has the apertures, which are made up either of one moving section or of two sections, one of them fixed and the other moving. The essential aspect of this part is that it should be movable, because it is the part that controls how much air and light is admitted to the room. If it is made up of one section, it consists of panels that open sideways or slide upwards, and they may be either plain or perforated or have small sliding panels. If it is made up of two sections, they are usually sliding shutters, fig. 3. Louvres are also used in these sliding shutters to control air and light. In fact, if the openings were of sliding panels with louvres, the flow and amount of air is more controlled. These louvres govern the direction of the air in which it flows downwards into the room or upwards, as the householder wishes. That is, the appropriate number of louvres in the sliding shutter can be considered as a separate unit that can be controlled independently.

This part plays a great role in controlling most of the roshān's functions; including the view and penetrating air and light into the interiors. Sometimes, an extra lattice screen is used to conceal these apertures for more privacy. This extra screen, which called locally shish, is an indication of the family or women's presence. It could be added to the rawāshinn, as well as ordinary windows, to give the sense of another hanging, screened, projected box that could be seen as 'mini roshān', fig. 2, fig. 4. The shish is mainly designed to permit the occupants to see without being seen. It is a well-known element in the Hijaz region, as well as Sawakin and Egypt. Islamic architecture has maintained the use of these extra wooden screens when it is essential to open windows and balconies overlooking the street, as well as the inner courtyards in order to protect whoever is behind

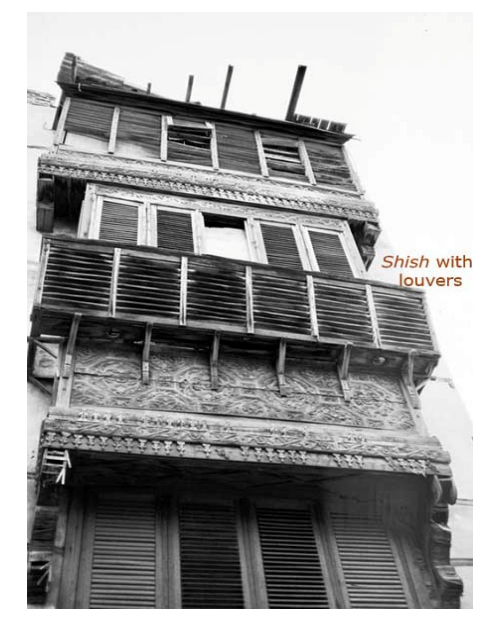

Figure 4: The shish and the louvers. 
them from the eyes of visitors and passers-by. This extra lattice screen, regardless of its local name, is used to cover apertures in the middle part of the windows and rawāshin alike. It is an extra screen layer which attaches to the openings to secure privacy.

\subsection{The upper part}

The upper part is made up of two sections, the upper window (shurra 'a $a$ ) and the top treatment. The shurrā'a is the upper part of the roshān connected to the apertures, or the middle part. It may be plain or partly perforated, (i.e. plain parts and perforated parts with holes arranged in a particular pattern) as in fig. 1, fig. 2. A plain shurrā'a is a horizontal surface, patterned or decorated with plant or geometrical designs which extend from the top of the apertures to the top of the whole roshān. A partly perforated shurrā'a consists of geometrical designs incorporating perforations which are a permanent source of light. The more perforations there are, the more light is admitted to the room, and usually clear or coloured glass is fixed from the inside to prevent dust from entering. It is sometimes possible to move the glass upwards or downwards to allow air to flow into the room. The top of the roshān is the last part above the shurrā' $a$ and takes various decorative forms from plain geometrical treatment to floral decorative crowns, fig. 2, fig. 3 .

These additional parts are extensions and trimmings used to decorate the top end, which act as a protective shield for the rawāshin. This top treatment could be a raffraf or a kind of umbrella for protection with a crown which is sometimes called burneita, fig. 3. In spite of the great quantity of woodwork in the roshān that extends outside, the three parts of its construction work as a whole to help the roshān's mechanism. These parts are designed to benefit the interiors of the house. The rawāshin act not only as air filters but also as light filters, since they regulate the entry of light and air alike. However, it is worth noting that the roshān may constitute the whole outer wall of the interior space, and this large area helps to combat inadequate lighting, but it also catches the breeze.

\section{The mechanism of the roshān}

The traditional roshān has fulfilled various desirable aims and purposes from ancient times because of its strength (of construction) and its continuity over many centuries with its wooden tracery so much in harmony with traditional Makkan houses. Each of its parts has a function and a purpose to achieve. Even the trimmings and additions complete the function and enrich it with beauty and decoration. From a practical point of view, the roshān is a window that looks out on the outside world and a screen veiling the light of the strongly blazing sun. It is a basic part of the building's air conditioning and part of the furnishing of the home. In some cases it is even an extension to some of the rooms above the street below. It acts as the centre of the family where most domestic activities take place. Such mechanism can fulfil the following benefits: 


\subsection{Achieving Islamic rules and social norms}

These are expressed in terms of privacy and the protection from outside intrusion of all that happens in the home apart from the roshān being an expression of relation between the inner and outer spheres. This privacy for the people living in the house protects them from the gaze of passers-by in the street while giving them the opportunity to follow what is happening outside. It provides the inhabitant with the possibility of looking out without allowing passers-by to see inside the house, either via small openings between the pieces of turned wood and other openings in the rawāshin, or through the narrow gaps and the openings in the geometrical designs in the roshān and the grill shish. The fact that it is darker inside than outside also helps to achieve this aim.

In this way, a woman in her private apartment inside the house can see life going on in the street outside without being seen by anyone, so that the rawāshin are considered an advantage to her. If she wants to look outside through the panels, she can see without being seen because the field of vision through the louvres when the screens are closed is about 90 degrees. This can be achieved by moving the louvres up or down, which gives great flexibility to the field of vision. The louvres at the same time break the line of vision and prevent whoever is inside from being seen.

Women are the significant factor between the roshān and the hijab (veil). Likewise the hijab as a concept governs the daily-life of women in Islam whereas the roshān, as an enclosure, is a screen masking the openings of the house. These screened windows are like the eyes of the house; having the windows screened will protect the interiors and will respect the householders' privacy. The hijab as a concept is the main character in Muslim daily life. Nevertheless, the veiling of women is just one form of a broader range of understanding of its implications. The word hijab, as a noun, comes from the Arabic verb hajaba, which means 'to hide from view or conceal'. It can mean to screen or draw a curtain or a barrier of any kind.

It is essential to have the windows open during the daytime in such a hot climate, but it is also essential not to jeopardize the privacy of the inhabitants. Consequently, the shish is added to the middle part of the roshān to keep this part open all the day for climatic reasons. These screens are attached to family rooms and wherever women occupy the rooms, fig. 4 . The middle part works as the eye and the nose of this cladding fabric; however, screens provide privacy and catch the breeze perfectly. These screens not just fulfil the demands of the hijab concept wholly, but they give other benefits such as observation and crossventilation.

This vision mechanism behind the roshān could be seen in this way: the inhabitant inside the house can observe the street by standing by the roshan, which has a shish attached to it. Being closer to the shish, from inside, allows the observer to see outside views clearly, but it is difficult to identify who or what is behind it, fig. 2, fig. 4 . This distance and the treatment of this part increases the angle of vision from inside, where the shish holds the middle part of the roshan creates a zone to control this mechanism, fig. 4. Considering the play of light and 
shadow on both sides, it plays a significant role in enhancing the view and creates a spectacular effect to the observer from both sides. The character of this analysis is based on the notion of more protection for women, where these extra lattice screens play a role in the visual analysis and work as barriers. This feature is attached to the roshān to give more protection and prevent vision intrusions to the interiors.

The rawāshīn with their alcoves, grids and openings also act as a means of interaction between the inner and the outer sphere, for it is possible for the residents of the house to make contact with the outside world without there being the least invasion of their domestic privacy. Therefore they can be psychologically relaxed while maintaining natural and correct relations between the people of the house and the outside society and environment around their residence. The roshān allows the resident of the house to use one's senses (hearing, sight and smell) to find out what activities and interactions and local events are taking place around the house simply and easily and without impediment. Thus the individual in his house is involved and connected with the society and the surrounding environment.

\subsection{Flexibility in a flow of air outward and inward}

The rawāshin are spread out as box-like units projecting into spaces outside, staggered both horizontally and vertically so that they cast their shadows on the façade of the building. They also help to reduce the amount of heat absorbed from the rays of the sun reflected from surfaces facing the building. The result of these variations in the amount and length of the projection to the outside from below to above with the depth of the rawāshin increasing with the height of the building, attracts the maximum amount of breeze to the higher levels above the street and the maximum amount of shade in the lower levels for most hours of the day.

Whether they extend to the outside at one level or several, these extensions increase with height, so they act as shades for the spaces outside and the lanes around the building, thereby shielding the passers-by from the rays of the sun in the lanes and between the buildings and also decreasing the amount of hot air entering the lower spaces during the day. The covered area then becomes like a trap for the air, allowing the minimum amount of hot air to enter while trapping breezes at the lower levels of the lanes and so cooling them. The walls try to absorb the air trapped in the area during the day to cool the interior space and the temperature of the walls falls, and the area becomes cooler as a consequence. It is as if the walls and the wood breathe during the night with a gentle breeze to cool the space.

The flow of air in the interior spaces is governed by the openings and apertures in the various kinds of rawäshin, as well as the shish -where it existsin such a way that these parts act as layers of filters for both the air and the dust. The openings in the roshān also admit the air to enter and be sucked to the interior, thereby reaching the various parts of the house. This could be either as a result of a drop in pressure in the vertical air passages, or by the house being built facing a direction which causes it to attract a breeze and create a flow of air 
in between that will penetrate the building. In addition, the broad exposed area of the roshān, with the shade in the upper end, makes the air move very slowly as it enters so that it carries only very little dust, as Khan [7] argues. Whereas if the openings are of sliding panels with louvres, the flow and amount of air is controlled because the variations in the way the louvres can be moved makes it easy to govern the direction in which the air flows downwards into the room or upwards, as the householder wishes. Similarly, the amount of air can be controlled by opening the appropriate number of louvres in the shutter/sliding panel; and each shutter can be considered a separate unit that can be controlled independently.

When the air flows and enters the inner space, the alcove of the roshān is the result of its extension outwards which creates an area where air can be transferred or distributed. That is, taking air in from the outside to distribute it inside across the adjacent seating area (called locally, dakka or a jalsa) in which one sits. Therefore the air, after being purified and filtered through the previous layers, reaches this area, which is the coolest area in the inner space because it is hollowed out in the wall and because of the thickness of the surrounding walls and because the breeze comes in through the openings in the roshann.

This constant entry of the outside air currents and their speed forces a quantity of air inwards and into the inner space as a whole. The direction of the flow makes it easy for the air to enter but difficult for it to get out, which keeps the inner space cool. This is a special benefit because the currents of air circle round in it and may collide if there are internal currents caused by a door or some such thing which helps cool the area further. The force of the current of air coming from outside is not matched by any internal current, and so the airflow is concentrated within.

\subsection{Maintenance of desirable temperature}

This is possible in the internal spaces as a result of the houses being isolated from the outside as far as temperature is concerned, where wood as a natural insulator prevents the burning rays of the sun reaching the building, except via the walls or through the openings and apertures. In addition, the staggered or regular projection of the rawāshin throws shadow onto the façade of the building and so limits the penetration of direct sunlight and the rays of the sun reflected from the surfaces facing it. Thus it helps the building to withstand heat from the outside, especially if the surfaces of the buildings facing each other are similar so that the two façades absorb the heat and insulate the area from the heat.

The bases of the rawāshin are designed to attract shade onto the building and the street to keep the temperature down while allowing in the shaded air so that it bounces off their angles and the walls become cooler, which helps the cooling of the interior of the building. The other parts of the roshan and the decorative extensions and trimmings also contribute to creating shadows and breaking the concentration of the direct rays of the sun, which are dispersed by striking these angles and cavities and irregular surfaces. 
At night, because of the thickness of the walls in traditional houses and the attempts of the morning sun to penetrate being prevented by the rawāshin, the temperature remains comfortable. This will be the case in the lower areas of the buildings that manage to retain their coolness through their proximity to the lower empty spaces which are comparatively cool because they are so little exposed to the sun's rays relative to the spaces on the upper floors. Although the rawāshin are large, the openings in them are appropriate to their size as if the projection of the roshān fishes for air in the sea outside, but remains in firm control.

\subsection{Control of the desired amount of light}

The rawāshīn act not only as air filters but also as light filters since they regulate the entry of light and brightness into the interior spaces and solve the problem of glare. This is even more controlled within the interior space if there are supplementary lattice screens and shish. In spite of the great quantity of woodwork in the rawāshin extending to the outside, the amount of light that penetrates to the interior may be considered to be under control because the various parts and assemblages of the rawāshin are sufficient to limit the strong natural light penetrating to the interior and so protect the residents from the problem of glare. If the shutters have louvres: it is obvious that the strong summer sun creates glare when the roshān is fully open. Therefore, the louvres are used to limit the glare so that the contrast between light and shade is acceptable and not a strain on the naked eye, fig. 5 .

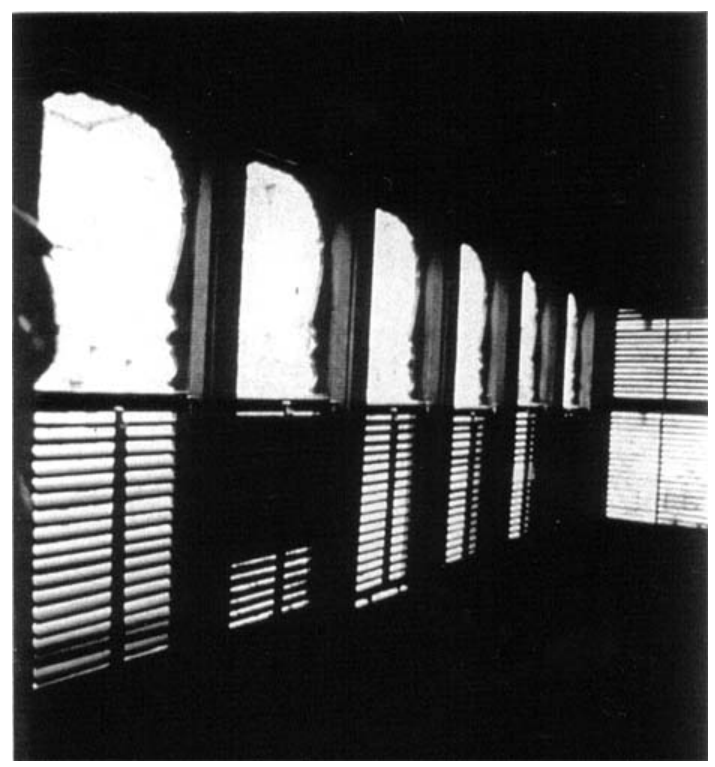

Figure 5: $\quad$ Louvres of the roshān from within [11]. 
On the other hand, if the shish is used, it helps to limit the amount of glare from the sunshine that enters into the rooms through these openings. That is, just as the rays and light of the sun are weakened many times over on the movable surfaces around the units, which allows a comfortable amount of light to enter the building without exposure to strong glare, especially in those desert areas where temperatures are very high. Furthermore, if the rawāshin have both louvres and shish, glare is limited by a system of louvres and lattice grid so that the light passes through the lattice grid and casts wonderful interwoven patterns on the interior decorated surfaces, camouflaging the outlines between their solid and open parts. Therefore, no sharp edges appear nor any violent contrasts between the dark colour of the walls and the brilliance of the light, so that the eye is not dazzled.

The amount and proportion of light can be controlled by closing and opening the shutters of the openings, regardless their various kinds. If the shutters are plain, it is the grill shish that performs the task of filtering the light and limiting the amount of interior illumination. According to Hariri [5] if the shutters have movable louvres, the light passes through these louvres in each wooden panel independently with a possible opening of up to about $40 \%$ of the surface of that panel. If more intense light is wanted, the shutter can be raised so that light can enter through the whole area of the shutter. Taking into consideration the fact that each roshān has at least twelve shutters, and each of them can be controlled separately, it is clear how much flexibility there is in the complete control over the intensity of the lighting. The roshān may constitute the whole outer wall of the interior space and this large area helps to combat inadequate lighting.

\subsection{Benefiting from the outward projection of the roshān}

It seems that the purpose in building rawāshīn and similar extensions is to increase the floor area of the upper storeys and to make the building more beautiful. It is likely that they should be made of wood or of materials that can resist natural conditions. The outward extension of the roshān casts more shadow and coolness on the areas around the external spaces. As for the inside, the large size of the roshān results in the expansion of the size of the room, thus affecting the general form of the interior space. The extension outwards may be of balanced proportions, or it may be more one side than the other and this has its effect, both inside and outside. The variations in the amount of overhang have particular advantages in terms of vision and give a better opportunity to break the line of vision from one building to another and one storey to another in the same building, as well as giving a real opportunity to see outside, taking advantage of a bend in the street.

From inside, this extra area has a liberating effect inside for it makes it possible to accommodate many domestic activities, such as eating, sitting and even sleeping. The roshān also guarantees the family's privacy as well as the opportunity for direct communication and interaction with the outside, while the lower shutters of the roshān starts from the eye level of someone sitting, easily achieving the aims set out above. Thus the effect of the roshān on the interior space is evident, and hence the inevitability of its effect on the interior design 
patterns, considering influence of its size, through its constituent materials, its form and decoration, on the interior areas of the traditional house, as well as its control of light, air and visibility.

\subsection{The aesthetic value of the general exterior appearance}

The general exterior appearance of the roshān has a number of qualities: Firstly, the general exterior appearance is like a unifying character that gives an aesthetic touch and a particular beauty to traditional houses in particular and to the lanes of the area in general. Although the design of the rawāshin differs for each building, they all keep the same spirit and concept giving to the urban environment its unity and identical character. This touch is the product of the various patterns with their contrasting and extremely precise forms. Similarly the general lines of the roshān and its design dominate the vertical plane in harmony with the vertical façades of the buildings.

The shutters have been designed in such a way that they do not lose their beauty whether they are open or closed to perform their various functions. Because these shutters slide vertically within channels (metal rings and loops) that specially carved out in them instead of opening inwards or outwards, thus not spoiling the general exterior appearance of the roshān, and the façade of traditional houses remains elegant at all times. The distribution of the rawāshin as either connected or separated units along vertical and horizontal axes, has a further aesthetic aspect. That is, it structures the general façade of the house, and the combination of the same kind of rawāshin, in either even or uneven arrangements on the houses of the area, or in the same lane. Such a pattern gives a different character, in spite of the variations in decoration, number and arrangement.

Secondly, the material used in making these rawāshin aids the creation of this particular kind of beauty. The strength and durability of wood and its adaptability to decoration plays a decisive part in the external character of the roshān, for the use of wood as the basic material over large surfaces creates a unity and harmony between buildings despite wide variations in measurements and details and decorations. According to Hariri [5] wood is a rich, warm material and teak (Javanese wood) is used to be dried in the sun before use for about three months to get rid of all moisture so that it would not swell or warp or split after being assembled.

Thirdly, the general distribution of the rawāshin and the artistry of their component parts naturally vary in kind and extent according to the means and taste of the householder. It generally indicates and mirrors the kind of residents occupying the houses. Therefore, the number of rawashin, the amount of decoration on them, their size, the kind of carving and embellishment used - the general appearance of the house, including doors, windows and façades - reflect the economic and social class of the owners. The richness of patterns and decoration, together with the exotic style of the rawāshin and the way they are arranged, depends on the use of foreign labour employed by a limited number of wealthy families, while the widespread simple and more common type found in the lanes of Makkah are the work of local carpenters, as Fadan [8] claims. 


\section{Conclusion}

The study of the roshān is not a call to return to the past; it is rather an open door to learn from the past and apply what is suitable, or what could be adopted, according to the new pace of life. The need is to comprehend the concept of the roshān in order to apply it or adapt it to a modern version. This is an attempt to rescue the notion of the roshān, because it proves its quality in such a hot and dry environment. It also fulfils Muslims' inhabitation requirements as Islamic rules dominate the essence of Islamic architecture.

The roshān has fulfilled various desirable aims and purposes from ancient times. Each part of the roshān's construction has a function and a purpose to achieve, including the trimmings and additions that enrich its beauty. The roshān is a window that looks out on the outside world and is a screen veiling the light of the strongly blazing sun. It is a basic part of the building's air conditioning and part of the furnishing of the home. In some cases it is even an extension to some of the rooms above the street. More importantly, the roshān is not merely an environmental feature; it is an absolute Islamic requirement for the sake of the household's privacy.

\section{References}

[1] Amin, Mohammed M. and. Ibrahim, Laila A. al-Mustalahat al-Mimariyya fi al-watha 'iq al-mamlukiyya, al-Jam'ia al-Amrikiya: al-Qāhira, 1990.

[2] Al-Murahhem, Faredah, Behind the Roshān: Visualising the Roshān as an Architectural Experience in Traditional Domestic Interiors, Unpublished PhD thesis. Brighton University: Brighton - UK, 2008.

[3] Al-Harithi, Nasir Ali, "A'mal al-Khashab al-Mi'mariyah Fi al-Hijaz Fi al-Asar al-Uthmani: Dirasa Faniya Hadariya." Unpublished master thesis, Umm al-Qura University, 1986.

[4] Greenlaw, Jean-Pierre. The Coral Buildings of Suaken. Oriel Press Ltd.: London-UK, 1976.

[5] Hariri, Majdi M. "Tasamim Al-Rowshan wa Ahamiyatahu Li Almaskan". Majallat Umm Al-Qura. 5.3, 1991, Pp 175-237.

[6] Taha, Hatim Umar, Taiyba wa Fanaha Al-Rafìy., Nadī al-Madina al-Adabī: Al-Madina, 1984.

[7] Khan, Sultan M., Manazil Jiddah Al-Qadìma, King Abdul Aziz Centre for Science and Technology: Riyadh - Saudi Arabia, 1986.

[8] Fadan, Yousef, Traditional Houses of Mekkah, the Influence of Socio-Cultural Themes upon Arab Muslim Dwelling", Islamic Architecture \& Urbanism, 1983.

[9] Al-Salih, Naser A., al-Mua'therat wal al-Anmat al-Geoghrafiya Lil 'Amarah al-Taqlidiya bil Mamlakah al-Arabiya al-Su'diya. Makkah: Umm al-Qura University, 1984.

[10] Miandji, Anooshirvan M., Farsi-English/English-Farsi Concise Dictionary, Hippocrene: New York, 2003.

[11] Hajj Research Centre, slides collection. Umm al-Qura University, Makkah. 